\title{
Sentidos atribuídos por adolescentes e jovens à saúde: desafios da Saúde da Família em uma comunidade vulnerável de Cubatão, São Paulo, Brasil
}

\author{
Meanings attributed by adolescents and young people \\ to health: challenges of Family Health in a vulnerable \\ community in Cubatão, São Paulo, Brazil
}

\author{
Danilo de Miranda Anhas \\ Universidade Federal de São Paulo. Programa de Pós-Graduação \\ Interdisciplinar em Ciências da Saúde. Santos, SP, Brasil. \\ E-mail: danilo-anhasळhotmail.com \\ Carlos Roberto de Castro-Silva \\ Universidade Federal de São Paulo. Departamento de Políticas \\ Públicas e Saúde Coletiva. Santos, SP, Brasil. \\ E-mail: carobert3ळhotmail.com
}

\section{Resumo}

Este artigo, baseado em pesquisa de mestrado, realizada entre 2013 e 2015, em uma comunidade vulnerável, a Vila dos Pescadores, em Cubatão (SP), visa a apresentar os sentidos atribuídos à saúde por adolescentes e jovens, assim como à Unidade de Saúde da comunidade, tendo como sujeitos do estudo os próprios adolescentes, jovens e adultos inseridos em trabalhos comunitários. A construção dos resultados, balizados pela metodologia da hermenêutica de profundidade, baseou-se nos diários de campo, produzidos a partir da observação participante, e em entrevistas com jovens e adultos inseridos no contexto de uma organização não governamental (ONG) e em um grupo de capoeira. Os resultados mostram a percepção de adolescentes e jovens quanto à influência de determinantes sociais na saúde, mencionando-se as dificuldades encontradas por esses sujeitos em perceber a Unidade de Saúde da Família do bairro como espaço de produção e promoção de saúde. Apesar de os resultados mostrarem também que não há articulação entre unidade de saúde com a ONG e o grupo de capoeira, estes últimos mostram grande potencial para promover saúde. Prevalecem ainda os desafios de se pensar as ações em saúde para essa população de forma acessível, integral, intersetorial e a partir das vivências e experiências dos próprios sujeitos.

Palavras-chave: Promoção à Saúde; Juventude; Vulnerabilidade. 


\section{Abstract}

This article, based on a master's research, carried out between 2013 and 2015, in a vulnerable community, the Vila dos Pescadores, in Cubatão (SP), Brazil, aims to present the meanings attributed to health by adolescents and young people as well as to the Health Unit, having as subjects the adolescents themselves and adults involved in community work. The construction of the results, based on the methodology of depth hermeneutics, was based on field diaries, produced from participant observation, and interviews with young people and adults inserted in the context of a Non-Governmental Organization (NGO) and in a Capoeira Group. The results show adolescents and young people's perception about the influence of social determinants in health, mentioning the difficulties encountered by these subjects in perceiving the Family Health Unit of the neighborhood as a space for production and health promotion. Although the results also show that there is no articulation between the Health Unit with the NGO and the Capoeira Group, the latter show great potential to promote health. The challenges of thinking about health actions for this population in an accessible, integral, intersectoral way and based on the experiences of the individuals themselves prevail. Keywords: Health Promotion; Youth; Vulnerability.

\section{Introdução}

A Estratégia Saúde da Família (ESF) resultou da implantação do Programa Saúde da Família de 1994, que, segundo Rosa e Labate (2005), tinha como proposta reorientar o modelo de assistência em saúde no país. A ESF lança-se ao desafio de efetivação dos princípios do Sistema Único de Saúde (SUS), pois entende que as ações em saúde precisam ser integradas e capazes de refletir a realidade dos usuários do serviço, intervindo nela. Embora em muitos locais o PSF tenha reorganizado e reorientado o serviço e as divisões de tarefas, atualmente, a partir da ESF, visa-se corrigir a fragmentação e a cisão dos saberes em saúde a fim de produzir cuidados e projetos terapêuticos com práticas dialógicas entre usuários e profissionais e entre os próprios profissionais (Rosa; Labate, 2005).

No âmbito dessas políticas estão adolescentes e jovens, usuários dos serviços de saúde na atenção primária. Por meio, por exemplo, das Diretrizes Nacionais para a Atenção Integral à Saúde de Adolescentes e Jovens na Promoção, Proteção e Recuperação da Saúde (Brasil, 2010), ratificam-se, no atendimento a esses indivíduos, princípios do SUS como, por exemplo, a intersetorialidade e a integralidade, trazendo também o enfoque de proteção integral para esses sujeitos, contido, sobretudo no Estatuto da Criança e do Adolescente (Brasil, 1990; Mello, 1999).

Reconhecem-se assim adolescentes e jovens como sujeitos de direitos que requerem práticas integrais que contribuam positivamente com seu desenvolvimento. Há, desse modo, segundo Silva e Silva (2011), reconhecimento desses indivíduos como destinatários e promotores de políticas públicas, sendo necessário garantir sua autonomia, ou seja, que possam ser sujeitos que constroem sua própria história e do mundo onde vivem (Castro, 2009). Ressalta-se a importância de o Estado ser o zelador desses mesmos direitos, rompendo com a distância existente para com adolescentes e jovens (Mello, 1999).

Fonseca e Ozella (2010) apontam em seu artigo a necessidade de estudos que estabeleçam e busquem compreender a relação desses sujeitos com a saúde, tendo em vista que ainda parece predominar no cuidado a esses indivíduos uma visão biologista e 
patologizante dessas etapas da vida. Assim, como afirmam Vieira et al. (2014), a ESF pode auxiliar na reconfiguração do modelo de atenção e cuidado do adolescente e do jovem, ao partir de uma abordagem mais ampla em saúde, incorporando processos para além dos fatores biológicos.

Essa visão corrobora com uma abordagem para além daquela que enxergava adolescentes e jovens como grupos de risco, predominante em cadernos do Ministério da Saúde e artigos científicos publicados entre os anos de 1989 e 2009 e estudados por Horta e Sena (2010). A visão fragmentada e a forma como se percebem esses indivíduos direcionam as ações em saúde. Se visto como grupos de risco, as ações em saúde tendem a ser coercitivas, compensatórias e corretivas, segundo as autoras.

A noção de vulnerabilidade passou a ser destacada nos anos 1980, sobretudo no campo de estudos de prevenção da aids. Buscou-se com esse conceito superar a ideia de risco social, que possuía um caráter fragmentado, probabilístico, focado no indivíduo e não no contexto social (Monteiro, 2011). Passou-se, desse modo, a entender a saúde a partir de questões físicas, psíquicas, sociais, culturais e econômicas (Ayres, 2010), recolocando os indivíduos em sua relação com o coletivo (Muñoz Sánchez; Bertolozzi, 2007).

Em estudo sobre a vulnerabilidade que adolescentes e jovens vivem no Brasil, Pessalacia, Menezes e Massuia (2010) apontam a importância desses serem compreendidos em suas necessidades e das ações em saúde acontecerem holisticamente, seguindo, sobretudo, o princípio de integralidade. Segundo Fonseca et al. (2013), ao estudar também as vulnerabilidades da infância e adolescência no país, o conceito de vulnerabilidade surge na América Latina para dar conta de explicar e compreender como vivem as pessoas. Desse modo, a ideia de vulnerabilidade está associada às dificuldades, mas também às potencialidades que indivíduos têm ou podem encontrar em interferir em sua própria saúde (Fonseca et al., 2013; Monteiro, 2011).

Embora a Organização Mundial da Saúde tenha ampliado em 1948 o conceito de saúde, as condições em que vivem crianças e adolescentes no Brasil parecem contradizer completamente o que se preconiza e recomenda. No Brasil são muitas as vulnerabilidades vividas por uma enorme parcela de adolescentes e jovens: uso de drogas e álcool, mortes devido a causas externas, violência, tráfico, desemprego, bairros sem infraestrutura e ausência de equipamentos e serviços públicos, exploração sexual e prostituição, abandono e negligência e trabalho forçado (Fonseca et al., 2013). Cita-se, por exemplo, o número de homicídios entre sujeitos de 15 a 24 anos, que aumentou 31,3\%, de 13.186 para 17.132 casos de 1996 a 2006, além do alto consumo de álcool e outras drogas na faixa etária de 9 a 24 anos de idade (Brasil, 2010).

Esse panorama parece intensificar dificuldades de superação de um modo estereotipado de enxergar o período da adolescência e da juventude como uma fase de rebeldia, turbulências e conflitos. Como salientam Castro (2008, 2009) e Ozella e Aguiar (2008), há que se pensar a adolescência e a juventude como processos de construções sociais, históricas e culturais. Estudos como de Germano e Colaço (2012) apontam para a importância do estabelecimento de diálogo com esses indivíduos, que vivem vulnerabilidades, mas que possuem potencialidades. Assim, a ideia sobre a incapacidade desses sujeitos autonomamente gerirem suas vidas torna rudimentar a construção de participação e, por conseguinte, da promoção de saúde.

Segundo Machado et al. (2007), a promoção de saúde engloba a articulação de diferentes saberes e atores sociais, Estado, instituições e políticas públicas, requerendo e reforçando a existência de processos democráticos e de participação. Promover saúde, segundo Czeresnia (2003), vai além da mera aplicação de técnicas, enfatizando-se a transformação da condição de vida das pessoas por meio de sua própria autonomia e de um Estado que desenvolva ações em âmbito global. Nesse sentido, tem-se a possibilidade de os indivíduos poderem intervir em seu próprio cuidado em saúde. Assim, a promoção de saúde acompanha a mudança de paradigma do próprio conceito de saúde, que foi ampliado.

O Ministério da Saúde (Brasil, 2010) chega a afirmar que favorecer a participação juvenil é uma forma de promover a saúde dessa população, alegando que a "participação ativa dos jovens no planejamento, execução e avaliação das ações de saúde contribuirá decisivamente para a eficácia, 
a resolutividade e o impacto social das mesmas" (p. 53). No entanto, em vista de alguns fatores comentados anteriormente, ainda é um desafio fazer essas palavras se traduzirem em ações reais.

Este artigo, produto de uma pesquisa de mestrado realizada entre os anos de 2013 e 2015 em uma comunidade vulnerável, a Vila dos Pescadores, em Cubatão (SP), visa a apresentar os sentidos atribuídos à saúde de adolescentes e jovens desse bairro, assim como à Unidade de Saúde da comunidade, tendo como sujeitos do estudo os próprios adolescentes, jovens e adultos inseridos em trabalhos comunitários com foco nesse público. A pesquisa foi realizada em duas instituições não governamentais, nas quais foram abordadas questões relativas à saúde na comunidade e à percepção da Unidade de Saúde da Família (USF) pelos participantes. Tem-se como desafio discutir as dificuldades encontradas por esses sujeitos em perceber a USF do território como espaço de produção e promoção de saúde.

\section{Procedimentos metodológicos}

Trata-se de uma pesquisa de abordagem qualitativa em ciências sociais, que traz em seu bojo o desejo de compreender a realidade social estudada a partir de sua historicidade e das próprias relações estabelecidas entre o pesquisador e os participantes do estudo, interpretando o universo de significados e sentidos (Minayo et al., 1994) com vistas à construção do conhecimento aqui apresentado.

Neste artigo, entende-se por "comunidade" aquela que se configura a partir de uma correlação de forças atuantes em um coletivo, produzindo conflitos, tensões, negociações, convergências e divergências. É muito mais que o espaço geográfico delimitado onde habitam as pessoas: consiste no espaço do cotidiano onde se objetivam as relações sociais, vinculando os indivíduos a territórios físicos ou simbólicos (Costa; Castro e Silva, 2015; Sawaia, 2010).

Alguns agentes comunitários de saúde da USF da comunidade apoiaram o reconhecimento do bairro e a localização das duas instituições nas quais foi realizado o estudo durante suas primeiras etapas. Cabe frisar que a pesquisa não foi feita dentro da unidade de saúde, em seu espaço institucional.
Foram realizadas 19 visitas a campo entre os meses de dezembro e março de 2014; as informações foram organizadas em 19 diários de campo, posteriormente analisados segundo a metodologia mencionada. Além das visitas a campo, que utilizaram como instrumento a observação participante, foram realizadas sete entrevistas semiestruturadas com moradores do bairro inseridos nas duas instituições examinadas. As entrevistas foram gravadas, transcritas na íntegra e analisadas sob a luz da hermenêutica de profundidade.

Consideraram-se jovens sujeitos com idades entre 15 e 29 anos, segundo o Estatuto da Juventude (Brasil, 2013) e adolescentes sujeitos com idades de 12 a 18 anos, de acordo com o Estatuto da Criança e do Adolescente (Brasil, 1990). As visitas a campo foram realizadas em dois locais distintos. 0 primeiro foi um Grupo de Capoeira, atuante na comunidade desde os anos 1980 e que realizava suas atividades com crianças, adolescentes e jovens na Associação dos Moradores da Vila dos Pescadores. Desse grupo foram entrevistados Guilherme, com 21 anos e aluno do grupo, e o professor de capoeira voluntário, Hugo, de 26 anos. O presidente da Associação de Moradores, Valdo, 50 anos, também foi entrevistado acerca de sua percepção sobre a juventude e a saúde no bairro.

O estudo também foi realizado em uma organização não governamental (ONG) que também atende crianças e adolescentes da comunidade desde a década de 1980. A ONG desenvolve atividades artístico-culturais com adolescentes de 12 a 18 anos de idade. Na ONG, foram entrevistados dois adolescentes: Luciano, 16 anos e Bárbara, 14 anos, além de uma das monitoras, Tia Bianca, 32 anos, e a psicóloga Luciana, 31 anos. Vale ressaltar que os nomes aqui apresentados foram alterados para preservar a identidade dos sujeitos.

Utilizou-se como metodologia de construção dos resultados a hermenêutica de profundidade, que consiste em três patamares de análise: (1) sócio-histórico: análise do contexto social; (2) formal ou discursivo: análise dos sentidos e significados que são compartilhados entre os sujeitos; (3) interpretação/reinterpretação: esta última etapa se chama assim pois se entende que os sujeitos de um estudo já interpretaram sua realidade, cabendo 
ao pesquisador reinterpreta-la, articulando-a com outras teorias e outros conceitos.

O estudo, sob parecer $n^{0} 473.514$ do Comitê de Ética em Pesquisa da Universidade Federal de São Paulo, teve também aval da Secretaria Municipal de Saúde de Cubatão (SP).

\section{Vila dos Pescadores}

Cubatão é uma das nove cidades que compõem a chamada Região Metropolitana da Baixada Santista. Segundo o Instituto Brasileiro de Geografia e Estatística (IBGE, 2016), no ano de 2010 o município possuía uma população de 118.720 habitantes e sua principal atividade econômica era a industrial. Na cidade, 2.127 pessoas são apontadas como vivendo em situação de vulnerabilidade social alta e 36.314 em situação de vulnerabilidade social altíssima (IPVS, 2016). A população na faixa etária de 10 a 24 anos de idade é de 31.680 (IBGE, 2016), representando $26,8 \%$ da população total.

Antes conhecida como Vila Siri, hoje a chamada Vila dos Pescadores (VP) é a comunidade na qual foi realizada a pesquisa de mestrado de Anhas (2015) e onde um grupo de docentes e alunos doutorandos, mestrandos e graduandos tem realizado atividades de pesquisa e extensão. 0 bairro recebe esse nome pois na década de 1960 grupos de pescadores se instalaram no local para realizar atividades de pesca, dado que o local é uma região de várzea rica em peixes e siris (Anhas, 2015).

Trata-se de uma comunidade periférica, construída sobre o mangue e na qual, segundo dados de 2006, 40\% da população sobrevivia com menos de um salário-mínimo. Na época, a população girava em torno de 10 mil habitantes, sendo que mais de $20 \%$ das moradias não tinham sistema de esgoto (Novo Milênio, 2014).

A comunidade lida com muitas dificuldades, sobretudo no âmbito da saúde. Nela, há uma USF construída nos anos 1980, a partir da organização comunitária dos moradores, que demarca praticamente a única presença do Estado na Vila dos Pescadores, assim como a polícia, que frequentemente realiza ações contra o narcotráfico, sendo vista pela maioria dos moradores como aquela que leva a violência para dentro da comunidade (Anhas, 2015).
Quanto mais próximo às margens do Rio Casqueiro, mais se pode observar moradias do tipo palafitas, que acabam por colocar em risco a integridade física das pessoas. Devido à ausência de sistema de esgoto tratado em grande parte do local, o cheiro de lixo, de dejetos e do próprio mangue é intensamente desagradável e incômodo. Aliás, há presença de muito lixo na comunidade. A coleta não é feita diariamente e o caminhão não consegue percorrer o território inteiro por falta de espaço, o que leva as pessoas que moram muito distante das caçambas a não jogar o lixo nesses recipientes, e sim nas águas do manguezal ou nos próprios becos. Crianças e adolescentes nadam nessas águas como forma de lazer, aumentando os riscos de doenças. Cabe dizer que há poucos espaços de lazer e de socialização na comunidade. Os poucos que existem, como a quadra de futebol, são majoritariamente ocupados por grande parte da população como espaço de usuários de drogas ou traficantes (Anhas, 2015).

Em meio às adversidades e à falta de opções para crianças, adolescentes e jovens, nos anos 1980 alguns membros da comunidade organizaram-se em prol de criar espaços para que estes sujeitos pudessem se manter afastados, sobremaneira, da criminalidade que já era intensamente presente no bairro.

O primeiro espaço no qual foi realizada a pesquisa foi o de uma ONG que atende crianças e adolescentes, realizando atividades culturais como dança, grafite, capoeira e curso de inglês. Essa organização possui dois prédios: o localizado na própria VP, que atende crianças de 4 a 11 anos e o localizado no bairro vizinho à VP, o Jardim Casqueiro, que atende adolescentes de 12 a 18 anos. A localização em outro bairro é, segundo a ONG, uma maneira de manter os adolescentes afastados da criminalidade, auxiliando-os a construir outras referências (Anhas, 2015).

O segundo espaço, também originado nos anos 1980 por iniciativa da própria comunidade, é um Grupo de Capoeira. O grupo realiza suas atividades no Centro Comunitário e é aberto para todas as faixas etárias. Entretanto, predominam adolescentes e jovens. Os mestres de capoeira foram formados na própria VP e trabalham voluntariamente. Todos os custos envolvidos na aquisição de instrumentos e uniformes são bancados pelos próprios alunos e professores (Anhas, 2015). 
São diversas as adversidades com as quais os moradores da VP lidam em seu cotidiano, vivenciando experiências de medo e tristeza. Esses afetos estão relacionados à potência de padecimento, aquela que diminui a potência e a capacidade de ação dos indivíduos, segundo Sawaia (2011), intensificando o sofrimento ético-político, sofrimento, esse, oriundo das injustiças sociais. Os sujeitos que trabalham com adolescentes e jovens nas instituições mencionadas referiram-se sempre ao medo de perder seus alunos para a criminalidade, que se mostra como uma importante opção entre escolhas escassas. Desse modo, ambas as instituições surgem na vida desses meninos e meninas como estratégia alternativa à falta de opções e referências que a comunidade apresenta, como uma maneira de enfrentamento.

\section{A saúde de adolescentes e jovens na Vila dos Pescadores}

Durante a execução de uma pesquisa coordenada pelo Prof. Dr. Carlos Roberto de Castro e Silva intitulada "A potência de ação de agentes comunitários de saúde na Estratégia Saúde da Família da Vila dos Pescadores no município de Cubatão"1 e de outros estudos realizados pelo grupo de pesquisadores e estudantes da Universidade Federal de São Paulo, campus Baixada Santista, ouvia-se dos profissionais de saúde que adolescentes e jovens não procuravam pelos serviços oferecidos na comunidade, mencionando a dificuldade de envolver esse público nas atividades cotidianas da instituição.

Ferrari, Thomson e Melchior (2006) referem a complexidade de se estabelecer as razões da distância de adolescentes e jovens, de uma maneira geral, dos serviços de saúde, seja pela pouca procura desses sujeitos pelos serviços ou pela baixa oferta de ações. Embora esses fatores estejam interligados, faz-se necessário compreender tal panorama.

Observando-se a ausência de adolescentes e jovens na USF, além da inexistência de atividades que tivessem esses sujeitos como público-alvo, tornou-se relevante entender os sentidos atribuídos à saúde de adolescentes e jovens moradores desse bairro, tanto a partir das vivências desses próprios sujeitos como das experiências de profissionais atuantes no Grupo de Capoeira e na ONG.

Vieira et al. (2014) propõem que o trabalho em saúde com adolescentes e jovens exige enfoques mais amplos, implicando na superação de uma visão meramente biologista dessa etapa do desenvolvimento humano, a qual é atravessada por questões biológicas, sociais, culturais, históricas e subjetivas. Os autores afirmam que a ESF pode ser um instrumento eficaz de atenção à saúde de adolescentes e jovens ao reorganizar o modelo de assistência, reafirmando os princípios de nosso SUS.

Dadas as características dessa etapa da vida, é importante conhecer e compreender as necessidades desse grupo social para que um diálogo possa ser efetivado no sentido de atender às suas demandas e necessidades, sendo esse um desafio para a integralidade no SUS (Marques; Queiroz, 2012). Nesse sentido, cabe ressaltar o desafio de se superar visões patologizantes da adolescência como período de turbulências, crises e rebeldia e enxergar esses sujeitos como possuidores de direitos.

0 trecho destacado a seguir ilustra algumas percepções dos jovens inseridos no Grupo de Capoeira sobre as condições de saúde na comunidade:

No Grupo de Capoeira, quando perguntei sobre questões de saúde da Vila dos Pescadores, responderam que as principais dificuldades são:

- Lixo que é jogado no mangue, desrespeitando o meio ambiente;

- Crianças e adolescentes que nadam no mangue/"maré" contaminado com o lixo arremessado pelos moradores;

- Ausência de lazer;

- Número cada vez maior de adolescentes grávidas;

- Existência de muitas moradias sem sistema de esgoto (Trecho do Diário de Campo, 2012). ${ }^{2}$

Ao relacionar saúde com as questões ambientais da comunidade, lazer e saneamento básico,

1 Projeto de pesquisa coordenado por Castro e Silva entre 2011 e 2013, sob o edital MCT/CNPq14/2011, na Universidade Federal de São Paulo. 2 Diário de campo do projeto de pesquisa “A potência de ação de agentes comunitários de saúde na Estratégia Saúde da Família da Vila dos Pescadores no município de Cubatão”. 
os jovens indicam possuir uma noção de saúde um tanto quanto ampliada, pois associam-na a outros fatores que vão além do biológico, referindo-se a seus determinantes sociais (Buss; Pellegrini Filho, 2007). Determinantes sociais de saúde estão relacionados aos comportamentos individuais e coletivos que influenciam na saúde das pessoas. Os fatores macroeconômicos, a cultura, a história, os hábitos, os costumes e fatores psicossociais são alguns elementos que ajudam a compreender como os determinantes sociais estão atrelados à saúde dos sujeitos.

Ademais, os adolescentes e jovens possuem vivências e conhecimento sobre a dinâmica e as características do território onde vivem. 0 reconhecimento do território, compreendido para além de suas dimensões espaciais e geográficas, permite o conhecimento acerca de processos sociais, econômicos, políticos e das relações entre as pessoas (Lima; Yasui, 2014; Monken; Barcellos, 2005). As vivências dos adolescentes e jovens no território da Vila dos Pescadores poderiam subsidiar a compreensão e caracterização desse grupo populacional, contribuindo, além disso, para a construção de vínculos entre esses sujeitos e o serviço de saúde.

No trecho da entrevista realizada com Luciano, o adolescente nos trouxe uma fala emblemática, na qual relaciona algumas questões da comunidade, como a violência e o conflito da polícia com o crime organizado e com a saúde. Devido às condições do contexto, as pessoas podem desenvolver problemas de saúde.

Tem umas [mães] que se sentem constrangidas, porque sofrem problemas médicos e a polícia já chega entrando, assustando, tem vez que já apontando a arma, já mandando pra parede dentro da própria casa. [...] $\varepsilon$ já chega colocando na parede dentro da sua casa, já quase batendo... Então daí, vamos supor, as mães vendo aquilo, a polícia fazendo aquilo com os próprios filhos dentro de casa que não têm nada a ver com o crime, elas sentem o coração, sei lá, amargurado, abatido. Tem umas que ficam até com pressão alta, nervosa, que já pensa: "A polícia vai levar meu filho e vai matar" (Luciano, 16 anos, aluno da ONG).

0 adolescente, com muita sensibilidade, relaciona alguns atos praticados por alguns membros da polícia contra sujeitos envolvidos com o tráfico de drogas como um fenômeno que influencia na saúde das mães. Quando os adolescentes e jovens demonstram possuir uma concepção ampliada de saúde, tendem a desejar que os profissionais da USF também as tenham e que coloquem em prática tais conhecimentos. Entretanto, assiste-se a um imobilismo por parte destes diante de questões e demandas desse grupo, concentrando-se na patologização e estigmatização desses meninos e meninas e indo de encontro às postulações da ESF para uma atenção integral.

Eu acho que eles procuram pouco porque é falta de conhecimento, né? $\varepsilon$ muitas vezes, igual eu escuto muitas vezes deles mesmos aqui: "Ah, tia, se eu tô magra eu tô com aids, se eu tô gorda eu tô grávida, se vocêvai no PAMOS [Postos de Atendimento Médico, Odontológico e Social] todo mundo acha que tu tá grávida". [Imitando as jovens] "Ah, tia, se a gente entra no PAMOS todo mundo fica falando que a gente tá grávida." Então já é um preconceito mesmo da população (Tia Bianca, 32 anos, monitora da ONG).

Como vemos nessa fala, Tia Bianca aponta para um preconceito da população contra a unidade de saúde - preconceito relacionado a uma falta de conhecimento do papel, da dinâmica e do funcionamento da instituição, sendo reforçado por uma ideia de que eles, os jovens, serão estigmatizados naquele lugar. Assim, tem-se uma lacuna de informação e conhecimento que parece reforçar o distanciamento desses sujeitos do equipamento, cabendo principalmente à USF a responsabilidade de se fazer ser reconhecida como espaço institucional acessível, acolhedor e produtor de saúde. Permanece o desafio de se romper barreiras financeiras, geográficas, culturais e simbólicas que impedem o acesso ao serviço pelos jovens dessa comunidade.

A compreensão das necessidades dos adolescentes e jovens da comunidade poderia interferir na boa qualidade dos atendimentos e serviços oferecidos a esse público, porém, essa compreensão tende a se tornar mais complexa dado o contexto em que as ações da USF acontecem. Como nos lembram Frutuoso et al. (2015) em pesquisa realizada no mesmo local, a USF/ESF demarca a presença e o papel do 
Estado naquele território - tal como a presença da polícia, que, nesse caso, é vista por muitos moradores da comunidade como aquela que leva a violência para o bairro. Como vimos no trecho de Luciano e em outros processos de construção do estudo, adolescentes e jovens são os principais atores envolvidos no tráfico de drogas, logo, são os principais alvos da polícia. A associação entre USF e polícia parece ser indireta, mas relaciona-se diretamente com o caráter público de ambas as instituições, já que representam o Estado. Outros fatores interferem ainda na visão do público como deficiente, a saber, a falta de acolhimento para com adolescentes e jovens, que parece leva-los a não procurarem pela USF da comunidade.

[A USF] é uma casa com duas pessoas. $\varepsilon$ tu entra assim, tipo, tu entra e num é bem recebido nessa casa. Tu entra nessa casa, tu senta na cadeira lá e tem mais dez visitantes. Veio isso na minha cabeça. Uns dez visitantes e tu esperando pra tu ser atendido bem e bem recebido (Guilherme, 21 anos, aluno Grupo de Capoeira).

Ah, porque, é falta de... de... de atendimento, o lugar é limpo, bem conservado, mas pra tu poder marcar uma consulta tem que ir um mês antes. [...] No dia de tu ir se consultar, o médico manda tu sentar lá na cadeira, olha pra tua cara, pergunta o que tu tem e nem te examina. $\varepsilon$ também [há] a falta de interesse deles de: "Ah, tô ganhando da prefeitura”. Falta de interesse (Guilherme, 21 anos, aluno do Grupo de Capoeira).

Por causa que lá, tem médico só que tu chega, tu senta, assim: "O que você tem?". Aí tu fala lá os teus sintomas, aí ele te olha: "Tá bom, toma uma benzetacil, tá bom, toma uma benzetacil, tá bom, toma uma benzetacil". Então, tipo, é sempre a mesma coisa (Bárbara, 14 anos, aluna ONG).

Além do esvaziamento do sentido que a USF ocupa na vida de adolescentes e jovens da comunidade, podemos pensar o quanto esse processo parece minar a participação desses sujeitos assim como práticas de promoção de saúde, entendidas, segundo Vieira et al. (2014) como "a capacitação da comunidade para atuar na melhoria da qualidade de vida e saúde, envolvendo maior participação no controle desse processo" (p. 310). Dessa forma, se "favorecer a participação juvenil é uma estratégia eficaz de promoção da saúde", como preconiza o Ministério da Saúde (Brasil, 2010, p. 53), como é possível construir práticas no âmbito da ESF que levem realmente esses preceitos em consideração?

$\mathrm{Na}$ atenção primária, o fortalecimento e a construção de vínculos estão associados a um bom acolhimento, que, de acordo com Giovanella e Mendonça (2012), refere-se a receber, escutar, oferecer proteção, dar amparo e resolver o problema apresentado. Entretanto, as falas dos adolescentes e jovens demonstram um panorama no qual eles não se sentem acolhidos nem compreendidos.

Em outro trecho, Valdo sintetiza o que tem se abordado até aqui acerca do distanciamento entre USF e comunidade. Para ele, existe a necessidade de que a equipe de saúde que trabalha na USF tenha compromisso com os moradores da comunidade. Ele reitera a questão de a unidade ser fechada para opiniões e sugestões. Utiliza a metáfora do "blinde" para ilustrar seu pensamento.

Então é complicado, cara, porque quando você leva uma ideia, olha, precisa mudar isso, ninguém te ouve. É fechado ali. O grupo se fecha e você não consegue entrar lá dentro. Você sente que tem um blinde ali, você não consegue penetrar. [...] Então eu procuro não me envolver. [...] Porque eu não vou mudar nada (Valdo, 50 anos, líder comunitário).

Segundo Giovanella e Mendonça (2012), um dos requisitos da atenção primária à saúde é que ela seja acessível e que sejam eliminadas barreiras financeiras, geográficas, organizacionais e culturais. Isso se faz necessário para que essa possa se efetivar como a porta de entrada do sistema de saúde.

O SUS preconiza que enxerguemos e atuemos na área de saúde considerando o ser humano em todas as suas dimensões; preconiza que tenhamos uma visão integral sobre os sujeitos, propondo ações contínuas de promoção, prevenção, atenção curativa, reabilitação e integração dos diferentes serviços. Ora, se partimos dessa ideia, torna-se, então, importante atuarmos também em nível 
intersetorial. Como nos lembra Cecílio (2006), a integralidade deve ser o objetivo da rede, e não apenas de uma instituição.

A ação intersetorial busca superar a fragmentação das políticas públicas e é entendida como a interação entre diversos setores no planejamento, na execução e no monitoramento de intervenções para enfrentar problemas complexos e necessidades de grupos populacionais. Em saúde, a articulação intersetorial é condição para que a atenção primária não se limite ao primeiro nível de atenção e seja capaz de incidir sobre os determinantes sociais do processo saúde-enfermidade e promover a saúde. Os resultados (finais ou intermediários) de saúde alcançados por meio da intersetorialidade são mais efetivos do que o setor saúde alcançaria por si só (Giovanella; Mendonça, 2012). Dessa maneira, ao atuar de forma intersetorial, os serviços em saúde não se restringem somente a aspectos biológicos, mas passam a contemplar outros fenômenos humanos.

A fala anterior explicita também que a intersetorialidade fica em segundo plano. Consideramos que ONG e Grupo de Capoeira são instituições que atuam promovendo saúde e possuem um potencial para a articulação com a unidade de saúde no contexto da atenção primária. Como já mencionado, promover saúde não consiste apenas na aplicação de técnicas Czeresnia (2003): a promoção enfatiza a transformação da condição de vida das pessoas por meio de sua própria autonomia. A ONG e o Grupo de Capoeira são instituições que demonstram potencialidades e a autossuficiência, atuando e intervindo na saúde de adolescentes e jovens. São dois exemplos nos quais se observa a possibilidade de os indivíduos poderem intervir em seu próprio cuidado em saúde. Porém, a articulação entre USF e esses grupos inexiste, como também lembrou a psicóloga da ONG:

Olha, assim, na saúde, a gente tenta fazer, assim, nas visitas que a gente faz, se percebe alguma coisa voltada à saúde a gente tenta sempre fazer o encaminhamento. Mas aí acaba que esbarrando quando vai pra prefeitura, alguns casos continuam, outros estacionam. Então, assim, a questão da saúde aqui no município de Cubatão tá muito precária. Entendeu? Acho que não tem os princípios dos SUS... (Luciana, 31 anos, psicóloga da ONG).
Deveria ter uma dinâmica assim, né? Pra chamar a atenção, alguma coisa a ser feita [...] e que seja em num horário de algum esporte, de capoeira, lá no centro comunitário. As porta tá aberta. Igual a sua pesquisa, as porta tá sempre aberta. Mas ninguém tá interessado em ir, em fazer alguma coisa fora do seu horário de trabalho, entendeu? Eles estão interessados ali, no horário deles de trabalho (Hugo, 26 anos, professor do Grupo de Capoeira).

Mas diante desse contexto, o que poderia fazer a USF da comunidade? Vimos que ela é retratada pelos participantes do estudo como uma instituição que não acolhe as demandas e as necessidades dos moradores do bairro, sobretudo as de adolescentes e jovens. Parece haver um distanciamento entre unidade de saúde e indivíduos, famílias e comunidade. A promoção do acesso aos serviços e a criação de vínculos entre a equipe e os usuários parece precária, e o impacto dos serviços oferecidos aos jovens, de pouco alcance. Tais circunstâncias vão na contramão do que é preconizado pelos princípios do SUS, que prevê integralidade e equidade.

Segundo Ayres et al. (2012), a integralidade constitui-se um desafio, pois instiga os profissionais da saúde a refletirem sobre o que e como fazer diante das necessidades de cada um, de uma maneira universal, propondo respostas a elas. Sendo atribuições da atenção primária à saúde a identificação, a articulação e a identificação de ações de saúde em determinada comunidade, é na USF que devem ser desenvolvidos serviços que atendam e acolham as necessidades de seus moradores.

Quando observamos todas essas adversidades que parecem levar a um afastamento de adolescentes e jovens da USF, percebemos também um vínculo fragilizado entre estes e a instituição propriamente dita. Acredita-se que deveria haver uma corresponsabilização dessa situação, apesar de a USF, com todas as suas dificuldades, atuar em uma comunidade de alta vulnerabilidade. As dificuldades, por exemplo, referem-se ao número reduzido de profissionais. Durante a fase de sondagem, a gerente da USF relatou haver áreas descobertas pela ESF. Entretanto, a USF é uma das poucas instituições que representam o poder público dentro da Vila dos Pescadores e é dela que precisa partir a produção 
do cuidado, para que o autocuidado, que também compõe a promoção à saúde, possa acontecer entre os moradores, destacando-se, aqui, os jovens.

Cabe à USF, portanto, desenvolver estratégias com a comunidade para a criação de canais de interlocução e escuta das necessidades dos jovens, bem como apreender, compreender e acolher as necessidades existentes, adequando-as aos serviços oferecidos. Torna-se preciso desenvolver uma escuta livre de preconceitos e sem condenação moral das necessidades de saúde dos sujeitos, como nos lembra Ayres et al. (2012). É preciso, ainda, que os jovens sejam incluídos como sujeitos de direitos, de maneira a eliminar as zonas de rupturas e os nós críticos existentes entre USF e esses sujeitos, em prol da promoção à saúde e prevenção de doenças, bem como no enfrentamento da desigualdade e exclusão sociais.

\section{Considerações finais}

A percepção dos jovens sobre a própria saúde e sobre a saúde na comunidade é bastante sensível e leva em consideração os determinantes sociais da saúde, ou seja, os fatores que têm dificultado a realização de suas potencialidades e a apropriação dos bens simbólicos e materiais.

Aos profissionais da saúde cabe o desafio de reorientar e articular suas práticas e serviços em consonância com as necessidades desses sujeitos, apontando-se aqui a importância de se considerar não apenas os determinantes sociais da saúde, mas como estes agem na vida desses adolescentes e jovens. Em vista da visão que os sujeitos denotam possuir acerca da saúde, torna-se de extrema relevância considerar suas experiências e vivências para fins de acolhimento e construção de vínculos e novas práticas.

Ressalta-se, além disso, a necessidade de levar em conta o princípio da ação intersetorial dentro da atenção primária à saúde, exercitando, assim, maior compreensão dos processos de saúde-doença e da articulação em rede. Salienta-se a importância do diálogo com adolescentes e jovens, levando-se em consideração os conhecimentos que eles possuem acerca da saúde, possibilitando enxergá-los para além de sua vulnerabilidade.
O desenvolvimento de projetos sociais na e pela comunidade já são indicadores das potencialidades existentes na comunidade da Vila dos Pescadores. O engajamento dos adolescentes e jovens nesses projetos realça tais potencialidades no que tange à participação social e à promoção à saúde.

\section{Referências}

ANHAS, D. M. Participação social, afetividade e subjetividade: as vivências de jovens moradores da Vila dos Pescadores em Cubatão/SP. 2015. Dissertação (Mestrado Interdisciplinar em Ciências da Saúde) - Universidade Federal de São Paulo, Santos, 2015.

AYRES, J. R. C. M. Vulnerabilidade e violência: a resposta social como origem e solução do problema. In: WESTPHAL, M. F.; BYDLOWSKI, C. R. Violência e juventude. São Paulo: Hucitec, 2010. p. 6o-72.

AYRES, J. R. C. M. et al. Caminhos da integralidade: adolescentes e jovens na Atenção Primária à Saúde. Interface: Comunicação, Saúde e Educação, Botucatu, v. 16, n. 40, p. 67-81, 2012.

BRASIL. Lei no 8.069, de 13 de julho de 1990. Dispõe sobre o Estatuto da Criança e do Adolescente e dá outras providências. Diário Oficial da União, Brasília, DF, 16 jul. 199o. Seção 1, p. 13563.

BRASIL. Ministério da Saúde. Diretrizes nacionais para a atenção integral à saúde de adolescentes e jovens na promoção, proteção e recuperação da saúde. Brasília, DF, 2010. Disponível em: <https:// goo.gl/luSfN>. Acesso em: 25 jun. 2016.

BRASIL. Lei ${ }^{0} 12.852$, de 5 de agosto de 2013. Institui o Estatuto da Juventude e dispõe sobre os direitos dos jovens, os princípios e diretrizes das políticas públicas de juventude e o Sistema Nacional de Juventude - SINAJUVE. Diário Oficial da União, Brasília, DF, 6 ago. 2013. Seção 1, p. 1.

BUSS, P. M.; PELLEGRINI FILHO, A. A saúde e seus determinantes sociais. Physis: Revista de Saúde Coletiva, Rio de Janeiro, v. 17, n. 1, p. 77-93, 2007.

CASTRO, L. R. Participação política e juventude: do mal-estar à responsabilização frente ao destino comum. Revista de Sociologia e Política, Curitiba, v. 16, n. 3o, p. 253-268, 2008. 
CASTRO, L. R. Juventude e socialização política: atualizando o debate. Psicologia: Teoria e Pesquisa, Brasília, DF, v. 25, n. 4, p. 479-487, 2009. COSTA, S. L.; CASTRO E SILVA, C. R. Afeto, memória, luta, participação e sentidos de comunidade. Pesquisas e Práticas Psicossociais, São João del-Rei, v. 10, n. 2, p. 284-294, 2015.

CECÍLIO, L. C. O. As necessidades de saúde como conceito estruturante na luta pela integralidade e equidade na atenção em saúde. In: PINHEIRO, R.; MATTOS, R. A. (Org.). Os sentidos da integralidade na atenção e no cuidado à saúde. 6. ed. Rio de Janeiro: IMS: UERJ, 2006. p. 115-128.

CZERESNIA, D. O conceito de saúde e a diferença entre prevenção e promoção. In: CZERESNIA, D. Promoção da saúde: conceitos, reflexões, tendências. Rio de Janeiro: Fiocruz, 2003. p. 39-53.

FERRARI, R. A. P.; THOMSON, Z.; MELCHIOR, R. Atenção à saúde dos adolescentes: percepção dos médicos e enfermeiros das equipes da saúde da família. Cadernos de Saúde Pública, Rio de Janeiro, v. 22, n. 1, p. 2491-2495, 2006.

FONSECA, D. C.; OZELLA, S. As concepções de adolescência construídas por profissionais da Estratégia de Saúde da Família (ESF). Interface: Comunicação, Saúde e Educação, Botucatu, v. 14, n. 33, p. 411-424, 2010.

FONSECA, F. et al. As vulnerabilidades na infância e adolescência e as políticas públicas brasileiras de intervenção. Revista Paulista de Pediatria, São Paulo, v. 31, n. 2, p. 258-264, 2013.

FRUTUOSO, M. F. P. et al. Gestão local de saúde em território de vulnerabilidade: motivações e racionalidades. Saúde em Debate, Rio de Janeiro, v. 39, n. 105, p. 337-349, 2015.

GERMANO, I. M. P.; COLAÇO, V. F. R. Abrindo caminho para o futuro: redes de apoio social e resiliência em autobiografias de jovens socioeconomicamente vulneráveis. Estudos de Psicologia, Natal, v. 17, n. 3, p. 381-387, 2012. GIOVANELLA, L.; MENDONÇA, M. H. M. Atenção primária à saúde. In: GIOVANELLA, L. et al.
Políticas e Sistema de Saúde no Brasil. Rio de Janeiro: Fiocruz, 2012. p. 493-546.

HORTA, N. C.; SENA, R. R. Abordagem ao adolescente e ao jovem nas políticas públicas de saúde no Brasil: um estudo de revisão. Physis: Revista de Saúde Coletiva, Rio de Janeiro, v. 20, n. 2, p. 475-495, 2010.

IBGE - INSTITUTO BRASILEIRO DE GEOGRAFIA E ESTATÍSTICA. Cidades: Censo de Cubatão. Brasília, DF, 2016. Disponível em: <https://goo. gl/7AF4TG >. Acesso em: 3 jul. 2016.

IPVS - ÍNDICE PAULISTA DE VULNERABILIDADE SOCIAL. Município de Cubatão. São Paulo, 2016. Disponível em: <https://goo.gl/8WTudr>. Acesso em: 6 jun. 2017.

LIMA, E. M. F. A.; YASUI, S. Territórios e sentidos: espaço, cultura, subjetividade e cuidado na atenção psicossocial. Saúde em Debate, Rio de Janeiro, v. 38, n. 102, p. 593-6o6, 2014.

MACHADO, M. F. A. S. et al. Integralidade, formação de saúde, educação em saúde e as propostas do SUS: uma revisão conceitual. Ciência \& Saúde Coletiva, Rio de Janeiro, v. 12, n. 2, p. 335342, 2007.

MARQUES, J. F.; QUEIROZ, M. V. O. Cuidado ao adolescente na atenção básica: necessidades dos usuários e sua relação com o serviço. Revista Gaúcha de Enfermagem, Porto Alegre, v. 33, n. 3, p. 65-72, 2012.

MELLO, S. L. Estatuto da Criança e do Adolescente: é possível torná-lo uma realidade psicológica? Psicologia USP, São Paulo, v. 10, n. 2, p. 139-151, 1999.

MINAYO, M. C. D. et al. Pesquisa social: teoria, métodos e criatividade. Petrópolis: Vozes, 1994. MONKEN, M.; BARCELLOS, C. Vigilância em saúde e território utilizado: possibilidades teóricas e metodológicas. Cadernos de Saúde Pública, Rio de Janeiro, v. 21, n. 3, p. 898-9o6, 2005. MONTEIRO, S. R. R. P. O marco conceitual da vulnerabilidade social. Sociedade em Debate, Pelotas, v. 17, n. 2, p. 29-40, 2011. 
MUÑOZ SÁNCHEZ, A. I.; BERTOLOZZI, M. R. Pode o conceito de vulnerabilidade apoiar a construção do conhecimento em Saúde Coletiva? Ciência \& Saúde Coletiva, Rio de Janeiro, v. 12, n. 2, p. 319-324, 2007.

NOVO MILÊNIO. Censo na Vila dos Pescadores é mais uma fase cumprida para a urbanização da área. 2014. Disponível em: <http://www. novomilenio.inf.br/cubatao/bvpescad3.htm>. Acesso em: 8 ago. 2014.

OZELLA, S.; AGUIAR, W. M. J. Desmistificando a concepção de adolescência. Cadernos de Pesquisa, São Paulo, v. 28, n. 133, p. 97-125, 2008.

PESSALACIA, J. D. R.; MENEZES, E. S.; MASSUIA, D. A vulnerabilidade do adolescente numa perspectiva das políticas de saúde pública. Bioethikos, São Paulo, v. 4, n. 4, p. 423-430, 2010. ROSA, W. A. G.; LABATE, R. C. Programa Saúde da Família: a construção de um novo modelo de assistência. Revista Latinoamericana de Enfermagem, Ribeirão Preto, v. 13, n. 6, p. 10271034, 2005.
SAWAIA, B. B. Comunidade: a apropriação científica de um conceito tão antigo quanto a humanidade. In: CAMPOS, R. H. F. (Org.). Psicologia Social Comunitária: da solidariedade à autonomia. Rio de Janeiro: Vozes, 2010. p. 35-53.

SAWAIA, B. B. O sofrimento ético-político como categoria de análise da dialética exclusão/ inclusão. In: SAWAIA, B. B. As artimanhas da exclusão: análise psicossocial e ética da desigualdade social. Rio de Janeiro: Vozes, 2011. p. 99-129.

SILVA, R. S.; SILVA, V. R. Política Nacional de Juventude: trajetória e desafios. Caderno $\mathrm{CRH}$, Salvador, v. 24, n. 63, p. 663-678, 2011.

VIEIRA, R. P. et al. Participação de adolescentes na Estratégia Saúde da Família a partir da Estrutura Teórico-Metodológica de uma Participação Habilitadora. Revista Latinoamericana de Enfermagem, Ribeirão Preto, v. 22, n. 2, p. 309-316, 2014.

\section{Contribuição dos autores}

Anhas foi responsável pelo estudo. Ambos os autores contribuíram na redação do artigo e análise dos resultados.

Recebido: 25/09/2016

Reapresentado: 10/05/2017

Aprovado: 29/05/2017 